\title{
(6) OPEN ACCESS \\ Team science as interprofessional collaborative research practice: a systematic review of the science of team science literature
}

\author{
Meg M Little, ${ }^{1}$ Catherine A St Hill, ${ }^{2}$ Kenric B Ware, ${ }^{3}$ Michael T Swanoski, ${ }^{1}$ \\ Scott A Chapman, ${ }^{2}$ M Nawal Lutfiyya, ${ }^{4}$ Frank B Cerra ${ }^{4}$
}

'Department of Pharmacy

Practice and Pharmaceutical Sciences, College of

Pharmacy, University of Minnesota, Minneapolis,

Minnesota, USA

${ }^{2}$ Department of Experimental and Clinical Pharmacology, College of Pharmacy,

University of Minnesota, Minneapolis, Minnesota, USA

${ }^{3}$ Department of Pharmacy Practice, College of Pharmacy, South University, Columbia, South Carolina, USA

${ }^{4}$ National Center for Interprofessional Education and Practice, Children's Rehabilitation Center, University of Minnesota, Minneapolis, Minnesota, USA

\section{Correspondence to} Dr M Nawal Lutfiyya, R685 Children's Rehab Center, 426 Church Street SE Minneapolis, MN 55455, USA

nlutfiyy@umn.edu

Accepted 13 August 2016 Published Online First 12 September 2016

Copyright (C) 2016 American Federation for Medical Research

\section{ABSTRACT}

The National Institute of Health's concept of team science is a means of addressing complex clinical problems by applying conceptual and methodological approaches from multiple disciplines and health professions. The ultimate goal is the improved quality of care of patients with an emphasis on better population health outcomes. Collaborative research practice occurs when researchers from $>1$ health-related profession engage in scientific inquiry to jointly create and disseminate new knowledge to clinical and research health professionals in order to provide the highest quality of patient care to improve population health outcomes. Training of clinicians and researchers is necessary to produce clinically relevant evidence upon which to base patient care for disease management and empirically guided team-based patient care. In this study, we hypothesized that team science is an example of effective and impactful interprofessional collaborative research practice. To assess this hypothesis, we examined the contemporary literature on the science of team science (SciTS) produced in the past 10 years (2005-2015) and related the SciTs to the overall field of interprofessional collaborative practice, of which collaborative research practice is a subset. A modified preferred reporting items for systematic reviews and meta-analyses (PRISMA) approach was employed to analyze the SciTS literature in light of the general question: Is team science an example of interprofessional collaborative research practice? After completing a systematic review of the SciTS literature, the posed hypothesis was accepted, concluding that team science is a dimension of interprofessional collaborative practice.

\section{INTRODUCTION}

The term team science has been used in multiple and diverse contexts. ${ }^{1-3}$ The National Institutes of Health's (NIH) concept of team science entails team members with training and expertise in different health profession fields working together to combine and integrate their knowledge, skills, and perspectives into single research projects that are clinically focused. ${ }^{1-3}$ Some have argued that clinical and translational science, grounded in NIH's concept of team science, is the gold standard for team science. ${ }^{4}$

\section{Significance of this study}

What is already known about this subject?

- Little has been written about team science as interprofessional collaborative research practice.

- Team science has led to the science of team science (SciTS) which is a meta-analysis or meta-understanding of team science including the understanding, management, and evaluation of team science conditions, collaborative processes, and outcomes to enable translation of research findings into new scientific knowledge, advances, clinical practices, and policies.

- Interprofessional collaborative research practice occurs when disciplinarians or practitioners from more than one health-related profession engage in scientific inquiry to jointly create and disseminate new knowledge to health professionals in order to provide the highest quality of patient care to improve patient-level and population-level health outcomes.

- To date, interprofessional collaborative research practice and team science have developed along separate paths rather than an integrated one even though team science in many ways is interprofessional collaborative research practice.

What are the new findings?

- After completing a systematic review of the SciTS literature, we accepted the hypothesis that team science is an example of effective and impactful interprofessional collaborative research practice.

- Team science is a dimension of the larger domain of interprofessional collaborative practice.

- There currently is a paucity of interprofessional and/or interdisciplinary team-based research training for health professional students who are training to become researchers. 


\section{Significance of this study}

\section{How might these results change the focus of research or clinical practice?}

- After completing a systematic review of the SciTS literature, we accepted the hypothesis that team science is an example of effective and impactful interprofessional collaborative research practice, concluding that team science is a dimension of the larger domain of interprofessional collaborative practice.

- For team science to actually gain long-term traction in successfully translating the findings from interprofessionally generated science into team-based clinical care, scientific and research training must change to incorporate a meaningful interprofessional dimension to it.

- Very little research training is team based or interprofessionally based.

- Just as health professions students (pharmacy, medicine, nursing, dentistry, etc) need interprofessional training for team-based clinical practice, health-related professional students who are training to become researchers need interprofessional and/or interdisciplinary team-based research training.

It is NIH's conceptualization of team science that we abide by in this review paper.

Team science is a means of attending to complex clinical problems by applying conceptual and methodological approaches from multiple scientific disciplines and health professions. ${ }^{2} 3$ The evolution of team science has until recently been a missed opportunity for the field of interprofessional clinical practice and education (IPE). IPE has historically focused on educational interventions for prelicensure health profession students (eg, pharmacy, nursing, and medicine) in order to influence future clinical practice. ${ }^{5-8}$ Continuing professional education on interprofessional team-based care has also achieved some IPE traction, again with the focus on influencing clinical practice directly. With the focus on education interventions, team science has largely been overlooked as an example of interprofessional and interdisciplinary collaborative practice essential to the health professions and care of patients. The nature of the collaborative practice of team science is the creation of new knowledge through interdisciplinary research that is translatable to clinical practice. It has become increasingly clear that the ability of different health professionals to provide optimal care is dependent on the sharing of expertise, knowledge, and peer learning. ${ }^{9}$

One example of the importance and use of team science is the domain of evidence-driven patient care that entails integrating clinical expertise with current best available clinical evidence from well-designed systematic research. Such research often informs clinical guidelines that can then be transformed into effective evidence-based clinical practice. Ultimately, effective patient care results from the combination of interprofessional medical practice and transdisciplinary scientific knowledge. Traditionally, clinical guidelines have been driven by evidence (science) produced by unidisciplinary teams or by an individual researcher. ${ }^{10}{ }^{11}$ Additionally, clinical guidelines rarely provide direction for team-based care. ${ }^{12}{ }^{13}$ As clinical and health-related problems become more complex, there is an increasing need to rely on team science as the nidus to produce evidence for the best possible care of patients that integrates the knowledge from multiple disciplines ${ }^{14-16}$ and emphasizes the importance of team-based care. ${ }^{17-19}$

Team science has given rise to the field of the science of team science (SciTS). SciTS is the understanding, management, and evaluation of team science conditions, collaborative processes, and outcomes to enable translation of research findings into new scientific knowledge, advances, clinical practices, and policies. In contrast, team science is an initiative to promote collaborative and frequently crossdisciplinary approaches to scientifically answer clinically related research questions.

A 2008 special issue of the American Journal of Preventive Medicine was dedicated to the nascent field of the SciTS. In this issue, Stokols $e t a l^{15}$ noted that the SciTS had not as yet amalgamated as a recognized paradigm. They also distinguished between the SciTS and team science by noting that team science referred to research initiatives by collaborating scientists from multiple disciples or fields, whereas the SciTS studied the effectiveness and characteristics of team science. A 2008 article by Hall et $a l^{20}$ referenced a conference held by NIH's National Cancer Institute (NCI) in 2006 on the SciTS that focused on assessing the value of transdisciplinary research. The objectives of the NCI conference were to address ambiguities and gaps in the SciTS literature, promote greater integration of knowledge in the field, and identify key issues for future investigation. Team science, as referred to in these instances, ${ }^{1520}$ is grounded in the same definition that we are using in this research study.

IPE is interrelated and forms an essential nexus where at the very least two or more professions learn about, from, and with each other to enable effective clinical collaboration to improve patient and population health outcomes $^{5}$ by delivering the highest quality of care. ${ }^{6}$ In the IPE nexus, interprofessional education will lead to collaborative clinical practice which will in turn inform interprofessional education over time. To date, the IPE nexus and team science have developed along separate paths rather than an integrated one. Team science in many ways is collaborative research practice and belongs in the IPE nexus.

Collaborative research practice occurs when disciplinarians or practitioners from more than one health-related profession engage in scientific inquiry to jointly create and disseminate new knowledge to health professionals in order to provide the highest quality of patient care to improve patient-level and population-level health outcomes. $^{21}$ Research produces the evidence that guides empirically grounded clinical practice or evidence-based care. $^{22}$

The four features that characterize collaborative research practice can be converted into questions that can be answered. These questions are as follows: 
Table 1 Glossary of terms

\begin{tabular}{|c|c|}
\hline Terms & Definitions \\
\hline Team science & $\begin{array}{l}\text { Entails team members with training and expertise in different health profession fields working together to combine and } \\
\text { integrate their knowledge, skills, and perspectives into single research projects that are clinically focused }\end{array}$ \\
\hline IPE & $\begin{array}{l}\text { Occurs when learners of professionals from two or more health professions learn about, from and with each other to enable } \\
\text { effective clinical collaboration to improve health outcomes by delivering the highest quality of care }\end{array}$ \\
\hline $\begin{array}{l}\text { Continuing professional } \\
\text { education }\end{array}$ & $\begin{array}{l}\text { Structured educational activity(ies) designed and intended to support the ongoing development of health professionals to } \\
\text { maintain and enhance their competence in providing the best quality of care }\end{array}$ \\
\hline Evidence-driven patient care & Entails integrating clinical expertise with current best available clinical evidence from well-designed systematic research \\
\hline $\begin{array}{l}\text { Transdisciplinary scientific } \\
\text { knowledge }\end{array}$ & $\begin{array}{l}\text { Scientific research collaboration that entails the exchange of information, altering discipline-specific approaches, sharing } \\
\text { resources, and integrating disciplines to generate new knowledge }\end{array}$ \\
\hline SciTS & $\begin{array}{l}\text { Is the understanding, management, and evaluation of team science conditions, collaborative processes, and outcomes to } \\
\text { enable translation of research findings into new scientific knowledge, advances, clinical practices, and policies }\end{array}$ \\
\hline Collaborative research practice & $\begin{array}{l}\text { Occurs when researchers from more than one health-related profession engage in scientific inquiry to jointly create and } \\
\text { disseminate new knowledge to clinical and research health professionals in order to provide the highest quality of patient } \\
\text { care to improve population health outcomes }\end{array}$ \\
\hline
\end{tabular}

IPE, interprofessional clinical practice and education; SciTS, science of team science.

1. Is team science comprised of persons from more than one health-related profession who collaborate on research that leverages the perspectives and knowledge of the different health professions or disciplines?

2. Does team science foster sound scientific inquiry that takes into account, without compromising, the knowledge and expertise of multiple health professions?

3. Does team science create and disseminate new knowledge to health professionals from many disciplines?

4. Does team science provide a knowledge base/foundation for the highest quality of patient care and improved health outcomes incorporating interprofessional team-based care?

This paper answers each of these questions by examining the contemporary literature on the SciTS produced in the past 10 years (2005-2015) and relates the SciTS to the overall field of IPE, of which collaborative research practice is a subset. The central research question of this review paper was: Is team science an example of interprofessional collaborative research practice? In this regard, we hypothesized that team science is an example of effective and impactful interprofessional collaborative research practice.

\section{METHODS}

We employed a modified preferred reporting items for systematic reviews and meta-analyses (PRISMA) approach, ${ }^{23}$ which is organized by five distinct elements or steps: beginning with a clearly formulated question, using the question to develop clear inclusion criteria to identify relevant studies, an approach to appraise the studies or a subset of the studies, a summary of the evidence using an explicit methodology, and interpreting the findings of the review. The details of these five steps are described below.

Step 1: formulating the research question. Prior to conducting the literature search, the purpose of the study and a specific question were established, leading to the clarification of the inclusion criteria. Our question was: Is team science an example of interprofessional collaborative research practice? We refined the research question into the following hypothesis: team science is an important example of effective and impactful collaborative research practice.
Step 2: identifying the relevant work. The inclusion criteria emerged directly from the question guiding this review and were specified a priori. We chose to limit our literature search and subsequent analyses to published, peer-reviewed articles, from the time span of 2005-2015. We chose 2005 as the floor year because it was 1 year before the NCI conference, and we chose 2015 as the ceiling because that was the year we began our study. Unpublished literature was excluded from this review. Moreover, we chose to focus on the SciTS literature because that would assist in establishing the criteria of team science in order to compare it to our working definition of interprofessional collaborative research practice. Our literature search was further limited to papers written in English as well as only those that were health related. The identification of relevant literature was grounded by our adoption of NIH's definition of team science and SciTS.

PubMed and Google Scholar were queried in our literature search. Our search terms were different combinations of team science, interprofessional collaborative practice, the science of team science, and SciTS (the accepted acronym for the science of team science). The literature search was initiated using the terms 'team science as interprofessional collaborative practice'. It was subsequently refined to team

Table 2 Codes for defining criteria of interprofessional collaborative research practice

\begin{tabular}{ll}
\hline Code & Criteria description \\
\hline MD & $\begin{array}{l}\text { Multiple disciplinarians from more than one health-related } \\
\text { profession who collaborate on research that leverages the } \\
\text { perspectives and knowledge of the different health professions or } \\
\text { disciplines }\end{array}$ \\
KE $\quad \begin{array}{l}\text { Sound scientific inquiry that takes into account, without } \\
\text { compromising, the knowledge and expertise of multiple health } \\
\text { professions }\end{array}$ \\
Create and disseminate new knowledge to health professionals of \\
many stripes and disciplines \\
IPTC $\quad \begin{array}{l}\text { Provide a knowledge base/foundation for the highest quality of } \\
\text { patient care and improved population health outcomes } \\
\text { incorporating interprofessional team-based care }\end{array}$
\end{tabular}




\section{Original research}

science alone. We then searched using the terms 'science of team science', which was narrowed or refined to SciTS. The final search was conducted using the terms 'team science SciTS'. Patents and citations were explicitly excluded from our searches of the literature. For clarity purposes, a glossary of terms is provided in table 1.

Step 3: an approach to appraise the studies. To assess the selected papers, we created a table that included the full paper citation along with the four components of collaborative research practice. Two authors reviewed each article and a total of six authors reviewed the papers. In order to eliminate inter-rater bias as much as possible, the six authors were paired to each of the papers using a random pairing generator. Each author reviewed the paper individually to determine which, if any, of the four defining criteria were present and the overall inclusion criteria (defined in step 2). The authors reviewing each paper made a decision as to whether or not the manuscript should be included in the review. In total, 14 author pairs were generated, and each author reviewed between 6 and 18 papers each. Whenever there was consensus between both reviewers for all four categories, the paper was either included or excluded. When there was disagreement between the author pairs, the article was reviewed and discussed by all six reviewing authors and a final determination of inclusion or exclusion was made.

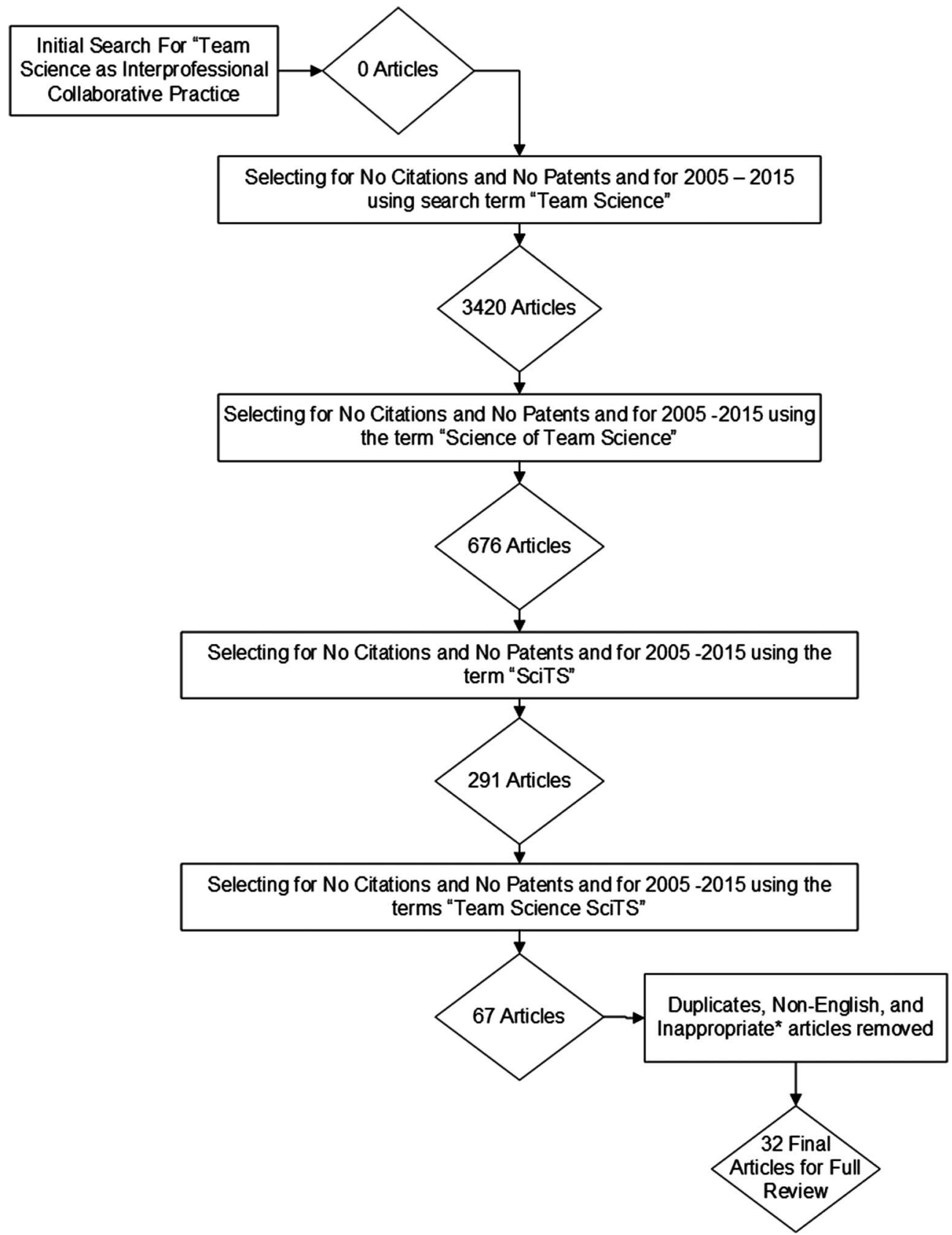

Figure 1 Science of team science article selection flow chart by reviewer inclusion criteria. SciTS, science of team science. *Inappropriate refers to website and tool kit review papers, non-health-related papers, editorials, and descriptions of tool kits. 
Baker B. The Science of Team Science An emerging field delves into the complexities of effective collaboration. BioScience 2015;65: 639-44

Begg MD, Crumley G, Fair AM, et al. Approaches to preparing young scholars for careers in interdisciplinary team science. J Investig Med 2014;62:14-25

Begg MD, Bennett LM, Cicutto L, et al. Graduate education for the future: new models and methods for the clinical and translational workforce. Clin Trans/ Sci 2015;8:787-92

Bennett LM, Gadlin H. Collaboration and team science. J Investig Med 2012;60:768-75

Börner K, Contractor N, Falk-Krzesinski HJ, et al. A multilevel systems perspective for the science of team science. Sci Transl Med 2010;2:49cm24

Disis ML, Slattery JT. The road we must take: multidisciplinary team science. Sci Transl Med 2010;2:22cm9

Falk-Krzesinski HJ, Börner K, Contractor N, et al. Advancing the science of team science. Clin Trans/ Sci 2010;3:263-6

Falk-Krzesinski HJ, Contractor N, Fiore SM, et al. Mapping a research agenda for the science of team science. Res Eval 2011;20:145-58

Fiore SM. Interdisciplinarity as teamwork how the science of teams can inform team science. Small Group Res 2008;39:251-77

Gray B. Enhancing transdisciplinary research through collaborative leadership. Am J Prev Med 2008;35:S124-32

Hall KL, Feng AX, Moser RP, et al. Moving the science of team science forward: collaboration and creativity. Am J Prev Med 2008;35:

S243-9

Hall KL, Olster DH, Stipelman BA, et al. News from NIH: resources for team-based research to more effectively address complex public health problems. Transl Behav Med 2012;2:373-5

Hall KL, Stokols D, Moser RP, et al. The collaboration readiness of transdisciplinary research teams and centers: findings from the National Cancer Institute's TREC year-one evaluation study. Am J Prev Med 2008;35:S161-72

Hall KL, Stokols D, Stipelman BA, et al. Assessing the value of team science: a study comparing center-and investigator-initiated grants. Am J Prev Med 2012;42:157-63

Hall KL, Vogel AL, Stipelman BA, et al. A four-phase model of transdisciplinary team-based research: goals, team processes, and strategies. Transl Behav Med 2012;2:415-30

Holmes JH, Lehman A, Hade E, et al. Challenges for multilevel health disparities research in a transdisciplinary environment. Am J Prev Med 2008;35:S182-92

Klein JT. Discourses of transdisciplinarity: looking back to the future. Futures 2014;63:68-74

Klein JT. Evaluation of interdisciplinary and transdisciplinary research: a literature review. Am J Prev Med 2008;35:S116-23

Leischow SJ, Best A, Trochim WM, et al. Systems thinking to improve the public's health. Am J Prev Med 2008;35:S196-203

Lotrecchiano GR. A dynamical approach toward understanding mechanisms of team science: change, kinship, tension, and heritage in a transdisciplinary team. Clin Trans/ Sci 2013;6:267-78

Lotrecchiano GR. The science-of-team-science, transdisciplinary capacity, and shifting paradigms for translational professionals. Journal of Translational Medicine and Epidemiology 2013;1

Mabry PL, Olster DH, Morgan GD, et al. Interdisciplinarity and systems science to improve population health: a view from the NIH Office of Behavioral and Social Sciences Research. Am J Prev Med 2008;35:S211-24

Mâsse LC, Moser RP, Stokols D, et al. Measuring collaboration and transdisciplinary integration in team science. Am J Prev Med 2008;35: S151-60

Puga F, Stevens KR, Patel DI. Adopting best practices from team science in a healthcare improvement research network: the impact on dissemination and implementation. Nurs Res Pract 2013;2013:814360

Ryan D, Emond M, Lamontagne ME. Social network analysis as a metric for the development of an interdisciplinary, inter-organizational research team. J Interprof Care 2014;28:28-33

Spring B, Hall KL, Moller AC, et al. An emerging science and praxis for research and practice teams. Transl Behav Med 2012;2:411-4 Stokols D, Hall KL, Taylor BK, et al. The science of team science: overview of the field and introduction to the supplement. Am J Prev Med 2008;35:S77-89.

Stokols D, Misra S, Moser RP, et al. The ecology of team science: understanding contextual influences on transdisciplinary collaboration. Am J Prev Med 2008;35:S96-115

Vogel AL, Stipelman BA, Hall KL, et al. Pioneering the transdisciplinary team science approach: lessons learnt from national cancer institute grantees. J Trans/ Med Epidemiol 2014;2:pii:1027

Weaver SJ, Rosen MA, Salas E, et al. Integrating the science of team training: guidelines for continuing education. $J$ Contin Educ Health Prof 2010;30:208-20

Wildman JL, Thayer AL, Pavlas D, et al. Team knowledge research emerging trends and critical needs. Hum Factors 2012;54:84-111 Winter SJ, Berente N. A commentary on the pluralistic goals, logics of action, and institutional contexts of translational team science. Transl Behav Med 2012;2:441-5

MD* KE† CD

$\checkmark \quad \checkmark \quad \checkmark$
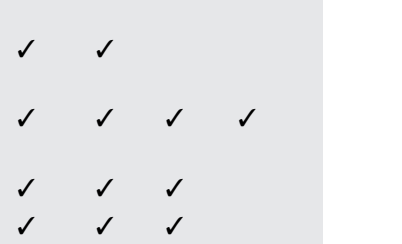

${ }^{*}$ Multiple disciplinarians from more than one health-related profession who collaborate on research that leverages the perspectives and knowledge of the different health professions or disciplines.

tSound scientific inquiry that takes into account, without compromising, the knowledge and expertise of multiple health professions.

¥Create and disseminate new knowledge to health professionals of many stripes and disciplines.

§Provide a knowledge base/foundation for the highest quality of patient care and improved population health outcomes incorporating interprofessional team-based care. SciTS, science of team science. 
Step 4: summarizing the presented evidence. Each of the 32 papers selected for final appraisal were coded by the four collaborative research practice criteria indicated by the codes MD, KE, CD, and IPTC (see table 2 for code definitions). Each article was coded according to which of the four defining criteria of interprofessional collaborative research were present. At least one of the criteria needed to be present for the paper to be included in the final analysis and this led to some of the articles being excluded from the analysis. During the coding process, disagreement occurred in over $50 \%$ of the papers. Disagreements were resolved by discussion and all six reviewers came to consensus.

Step 5: interpreting the findings. In the Discussion section, the findings of this review are interpreted. In addition, a summary of the current focus on the SciTS and interprofessional collaborative research practice is presented. We also offer suggestions for incorporating team science as interprofessional collaborative research practice into interprofessional health professions education and clinical practice.

\section{RESULTS}

The literature search was conducted in Google Scholar and PubMed. The initial search using the terms 'team science as interprofessional collaborative practice' yielded no articles. Selecting for 'no citations' and 'no patents' and searching for the term 'Team Science', 3420 items were returned. Refining the search term to the 'science of team science', 676 items were found. Using the acronym 'SciTS' as the search term, reduced the items to 291. An examination of these items quickly revealed that the acronym is used by other entities to represent information other than the examination of team science. This led to the use of our final search terms 'team science SciTS'. Using these final terms yielded 67 articles. Once duplicates, non-English papers, reviews of websites or tool kits, non-health-related papers, editorials and descriptions of tool kits were removed, 32 articles were included for review. Figure 1 displays a flow chart of this selection process. Table 3 provides information on the 32 SciTS articles included in this review. Also displayed in this table are the criteria of interprofessional collaborative research practice that was met by each article reviewed.

Table 4 displays a description of interprofessional collaborative research practice criteria coded per final articles reviewed $(n=32)$. The articles reviewed were classified according to the number of interprofessional collaborative research practice criteria identified in each article by the

Table 4 Frequency and per cent of interprofessional collaborative research practice criteria coded per article $(n=32)$

\begin{tabular}{lll}
\hline $\begin{array}{l}\text { Interprofessional collaborative research } \\
\text { practice components present }\end{array}$ & $\begin{array}{l}\text { Per } \\
\text { cent }\end{array}$ \\
\hline At least 4 & 12 & 37.6 \\
At least 3 & 18 & 56.3 \\
At least 2 & 2 & 6.3 \\
At least 1 & 0 & 0 \\
\hline
\end{tabular}

paired reviewers and after all disagreements were resolved. Articles containing at least three or at least four of the criteria together comprised the largest group (30 papers or $93.8 \%$ with 12 papers or $37.5 \%$ containing at least four criteria and 18 or $56.3 \%$ for at least three criteria). Two papers $(6.3 \%)$ were classified as containing at least two of the criteria and no papers $(0.0 \%)$ were classified as containing only one of the criteria.

Table 5 displays the frequency and per cent of the papers reviewed by each of the interprofessional collaborative research practice criteria coded by the reviewers. The first three criteria $(\mathrm{MD}, \mathrm{KE}$, and $\mathrm{CD}$ ) had high percentages of occurrence or code $(100 \%, 100 \%$, and $90.6 \%$, respectively). The fourth criterion (IPTC) was coded the least by the reviewers $(40.6 \%)$.

\section{DISCUSSION}

NIH's concept of team science is a means of addressing complex clinical problems by applying conceptual and methodological approaches from multiple disciplines and health professions. ${ }^{2}$ The ultimate goal is the improved quality of care of patients with an emphasis on better population health outcomes. We started this study hypothesizing that team science is an example of effective and impactful interprofessional collaborative research practice. After completing our systematic review of the SciTS literature, we believe that this hypothesis can be accepted, concluding that team science is a dimension of interprofessional collaborative practice. Specifically, interprofessional collaborative research practice allows disciplinarians or practitioners from more than one health-related profession to collaborate on research that leverages the perspectives and knowledge of different health professions or disciplines. ${ }^{24-26}$

We reviewed and analyzed the SciTS peer-reviewed articles because SciTS studies the effectiveness and characteristics of research teams engaged in scientific inquiry. Ultimately, SciTS was a better comparator to

Table 5 Frequency and per cent of papers containing each interprofessional collaborative research practice criteria coded $(n=32)$

\begin{tabular}{|c|c|c|c|}
\hline Code & Component description & Frequency & $\begin{array}{l}\text { Per } \\
\text { cent }\end{array}$ \\
\hline MD & $\begin{array}{l}\text { Multiple disciplinarians from more than } \\
\text { one health-related profession who } \\
\text { collaborate on research that leverages the } \\
\text { perspectives and knowledge of the } \\
\text { different health professions or disciplines }\end{array}$ & 32 & 100 \\
\hline KE & $\begin{array}{l}\text { Sound scientific inquiry that takes into } \\
\text { account, without compromising, the } \\
\text { knowledge and expertise of multiple } \\
\text { health professions }\end{array}$ & 32 & 100 \\
\hline$C D$ & $\begin{array}{l}\text { Create and disseminate new knowledge } \\
\text { to health professionals of many stripes } \\
\text { and disciplines }\end{array}$ & 29 & 90.6 \\
\hline IPTC & $\begin{array}{l}\text { Provide a knowledge base/foundation for } \\
\text { the highest quality of patient care and } \\
\text { improved population health outcomes } \\
\text { incorporating interprofessional } \\
\text { team-based care }\end{array}$ & 13 & 40.6 \\
\hline
\end{tabular}


Figure 2 Modified nexus.
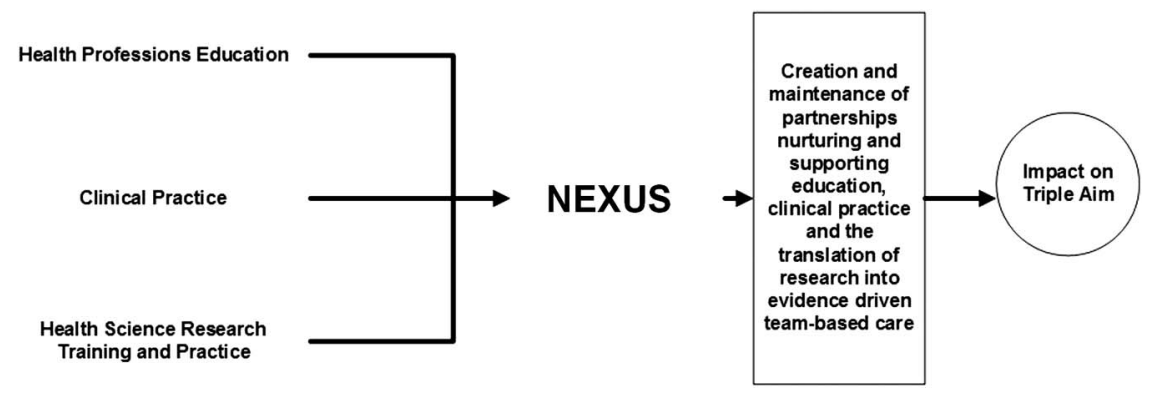

interprofessional collaborative research practice than was team science alone. Team science refers to research initiatives undertaken by collaborating scientists from multiple disciples or fields. Furthermore, we kept our focus on the realm of health professions and health-related clinical practice as initiated by the NIH in their team science approach. Accordingly, team science does foster sound scientific inquiry that takes into account the knowledge and expertise of multiple health professions.

In our analysis, three of our criteria defining interprofessional collaborative research practice- $\mathrm{MD}, \mathrm{KE}$, and $\mathrm{CD}-$ correlated highly (100\%, 100\% and 90.6\%, respectively) with the content of SciTS papers reviewed; therefore, team science creates and disseminates new knowledge to health professionals from many disciplines. Intriguingly, it was also the case that in our analysis of SciTS focused papers using the lens of our four-part definition of interprofessional collaborative research practice, one of our criteria was not present in $40.6 \%$ of the 32 articles reviewed. This neglected criterion was to provide a knowledge base/foundation for the highest quality of patient care and improved population health outcomes incorporating interprofessional team-based care. This is not to say that team science has neglected this-only that SciTS did not incorporate it fully in its analysis of team science. This is ironic given that a prominent goal of Clinical and Translational Science Awards (CTSA) is to develop teams of investigators from various fields of research who can take scientific discoveries and turn them into treatments and strategies for patients. ${ }^{26}$

One reason heretofore that team science has remained distant and separate from interprofessional collaborative practice is that it emerged and became established with NIH's funding of CTSA. This initiative by $\mathrm{NIH}$ was grounded in the dual recognition that some of the most cutting edge health science research takes place at the borders between disciplines and professions but the siloed efforts of researchers have propagated uniprofessional and individual research endeavors. ${ }^{24-26}$ Translational science funding was established to dismantle these research boundaries but in so doing neglected to conceptually connect team science with the field of IPE. In turn, once team science and SciTS became more established, the field of IPE missed the opportunity to embrace SciTS as an example of interprofessional collaborative practice focusing on clinical knowledge production through research.

Clearly, the increasing complexity of morbidity and the management of associated diseases and conditions require that health science researchers move beyond the boundaries of their own disciplines and professions ${ }^{25}$ in order to produce sound scientific evidence for the best possible

care of patients. In the field of IPECP, there has been a growing recognition that it is at the intersection of health professions education and clinical practice where population health outcomes will be most affected. The National Center for Interprofessional Practice and Education (NCIPE) at the University of Minnesota refers to this intersection as the nexus. ${ }^{27-30}$ There is a burgeoning recognition in the team science and SciTS literature ${ }^{19} 24$ that for team science to actually gain long-term traction in successfully translating the findings from interprofessionally generated science into team-based clinical care, scientific and research training must change to incorporate a meaningful interprofessional dimension to it. This approach is significant because research training is typically discipline specific (eg, epidemiology, pharmacy, medicine, nursing, etc) with some overlap in data collection, study design, and data analysis techniques. Very little research training is team based or interprofessionally based. Just as health professions students (pharmacy, medicine, nursing, dentistry, etc) need interprofessional training for team-based clinical practice, health-related professional students who are training to become researchers need interprofessional and/or interdisciplinary team-based research training.

IPE has focused on bringing interprofessional education and health professional training together with clinical practice. In contrast, team science has only recently started to merge interprofessional research training with translation into clinical practice. There are essentially two nexi that need to be integrated. The integration that we propose is depicted in figure 2. This is a modification of the depiction of the nexus currently used by the NCIPE. The nexus is expanded to bring together health professions education, clinical practice, and health sciences research training and practice. The long-term goal of this expanded nexus, then, is to impact the triple aim outcomes ${ }^{31}$ of improved population health, increased satisfaction with healthcare received, and reduced healthcare costs.

\section{CONCLUSIONS}

Our literature review of the SciTS clarified that team science itself is an essential dimension of interprofessional collaborative research practice. It is important going forward that team science be incorporated into an expanded understanding of the NCIPE's nexus in order to bring together health professions education, clinical practice, and health sciences research training and practice.

Competing interests None declared.

Provenance and peer review Not commissioned; externally peer reviewed. 
Open Access This is an Open Access article distributed in accordance with the Creative Commons Attribution Non Commercial (CC BY-NC 4.0) license, which permits others to distribute, remix, adapt, build upon this work noncommercially, and license their derivative works on different terms, provided the original work is properly cited and the use is non-commercial. See: http:// creativecommons.org/licenses/by-nc/4.0/

\section{REFERENCES}

1 National Cancer Institute's (NCI) Team Science Toolkit Website. http://www. teamsciencetoolkit.cancer.gov (accessed Dec 2015).

2 Cooke NJ, Hilton ML, eds, Committee on the Science of Team Science; Board on Behavioral, Cognitive, and Sensory Sciences; Division of Behavioral and Social Sciences and Education; National Research Council. Enhancing the effectiveness of team science. Washington (DC): National Academies Press (US), 2015.

3 Stokols D, Hall KL, Vogel AL. Transdisciplinary public health: definitions, core characteristics, and strategies for success. In: Haire-Joshu D, McBride TD, eds. Transdisciplinary public health: research, methods, and practice. San Francisco: Jossey-Bass, 2013:3-30.

4 Baker B. The science of team science: an emerging field delves into the complexities of effective collaboration. BioScience 2015;65:639-44.

5 World Health Organization. Framework for action on interprofessional education \& collaborative practice. World Health Organization, 2010:1-63.

6 Barr $\mathrm{H}$, Waterton $\mathrm{S}$. Interprofessional education in health and social care in the United Kingdom: report of a CAIPE survey. Fareham, UK: Centre for the Advancement of Interprofessional Education in Primary Health and Community Care, 1996.

7 Pellegrino ED. Educating for the health team. Arlington (VA): Institute of Medicine, 1972. http://eric.ed.gov/?id=ED110819

8 Baldwin DC. Some historical notes on interdisciplinary and interprofessional education and practice in health care in the USA. J Interprof Care 2007;21:23-37.

9 Mitchell P, Wynia M, Golden R, et al. Core principles and values of effective team-based health care. Discussion Paper. Washington (DC): Institute of Medicine, 2012. http://www.iom.edu/tbc

10 Timmermans $\mathrm{S}$, Kolker ES. Evidence-based medicine and the reconfiguration of medical knowledge. J Health Soc Behav 2004;45(Suppl):177-93.

11 Weisz G, Cambrosio A, Keating P, et al. The emergence of clinical practice guidelines. Milbank Q 2007;85:691-727.

12 Graham R, Mancher M, Wolman DM, Greenfield S, Steinberg E, eds. Clinical practice guidelines we can trust. Washington (DC): National Academies Press; 2011.

13 Doherty RB, Crowley RA. Principles supporting dynamic clinical care teams: an American College of Physicians position paper. Ann Intern Med 2013;159:620-6.

14 Patterson RE, Colditz GA, Hu FB, et al. The 2011-2016 Transdisciplinary Research on Energetics and Cancer (TREC) initiative: rationale and design. Cancer Causes Control 2013;24:695-704.
15 Stokols D, Hall KL, Taylor BK, et al. The science of team science: overview of the field and introduction to the supplement. Am J Prev Med 2008;35: S77-89.

16 Croyle RT. The National Cancer Institute's transdisciplinary centers initiatives and the need for building a science of team science. Am J Prev Med 2008;35:S90-3.

17 James PA, Oparil S, Carter BL, et al. 2014 evidence-based guideline for the management of high blood pressure in adults: report from the panel members appointed to the Eighth Joint National Committee (JNC 8). JAMA 2014;311:507-20.

18 Barr J, Fraser GL, Puntillo K, et al. Clinical practice guidelines for the management of pain, agitation, and delirium in adult patients in the intensive care unit. Crit Care Med 2013;41:263-306.

19 Begg MD, Crumley G, Fair AM, et al. Approaches to preparing young scholars for careers in interdisciplinary team science. I Investig Med 2014;62:14-25.

20 Hall KL, Feng AX, Moser RP, et al. Moving the Science of Team Science forward: collaboration and creativity. Am J Prev Med 2008;35:S243-9.

21 Hager KD, St Hill CA, Prunuske J, et al. Development of an interprofessional and interdisciplinary collaborative research practice for clinical faculty. $J$ Interprof Care 2016;30:265-7.

22 Shiffman RN, Shekelle P, Overhage JM, et al. Standardized reporting of clinical practice guidelines: a proposal from the Conference on Guideline Standardization. Ann Intern Med 2003;139:493-8.

23 Moher D, Liberati A, Tetzlaff J, et al. The PRISMA group preferred reporting items for systematic reviews and meta-analyses: the PRISMA statement. PLoS Med 2009;6:e1000097

24 Begg MD, Bennett LM, Cicutto L, et al. Graduate education for the future: new models and methods for the clinical and translational workforce. Clin Trans/ Sci 2015;8:787-92.

25 Lakhani J, Benzies K, Hayden KA. Attributes of interdisciplinary research teams: a comprehensive review of the literature. Clin Invest Med 2012;35: E226.

26 Clinical and Translational Science Awards (CTSA). Translating discoveries to medical practice. http://www.ctsaweb.org

27 Lutfiyya MN, Brandt BF, Cerra FB. Reflections from the intersection of health professions education and clinical practice: state of the science of interprofessional education and collaborative practice. Acad Med 2016;91:766-71

28 Garr DR, Margalit R, Jameton A, et al. Commentary: educating the present and future health care workforce to provide care to populations. Acad Med 2012;87:1159-60.

29 Cerra F, Brandt BF. Renewed focus in the United States links interprofessional education with redesigning health care. J Interprof Care 2011;25:394-6.

30 Brandt B, Lutfiyya MN, King JA, et al. A scoping review of interprofessional collaborative practice and education using the lens of the triple aim. $J$ Interprof Care 2014;28:393-9.

31 Berwick DM, Nolan TW, Whittington J. The triple aim: care, health, and cost. Health Aff (Millwood) 2008;27:759-69. 